\section{Exploring the Benefits of School Gardening for Children in Taiwan and Identifying the Factors Influencing these Benefits}

\author{
Yuan-Yu Chang ${ }^{1}$, Wei-Chia Su ${ }^{1}$, I-Chun Tang ${ }^{2}$, \\ and Chun-Yen Chang ${ }^{1,3}$
}

ADDITIONAL INDEX WORDS. qualitative research methods, general inductive approach, gardening benefits, children's horticulture

SUMMARY. There is a growing body of literature that explores the benefits of school gardening for children, but few studies have been conducted in Taiwan. Even fewer studies have examined which factors influence the benefits that children derive from these activities. Therefore, the purpose of this study was to explore the benefits of school gardening for children in Taiwan and also identify the factors influencing these benefits. This study used qualitative research methods, which consisted of interviewing 43 elementary school students who had extensive experience with gardening, and used a general inductive approach to analyze the data. The study also used a quantitative approach to statistically compare gender differences, which found that there were some differences in preference for gardening between boys and girls in Taiwan. The results also identify seven benefits children can derive from school gardening, including increasing life skills, producing pleasant feelings, improving relationships and having plants as companions, acquiring new knowledge, experiencing the aroma and flavor of fruits and vegetables, improving health, and increasing connection to nature. Some of these benefits of school gardening have not been mentioned in previous studies and can be considered to be new, such as having plants as companions. Additionally, this study found $\mathbf{2 0}$ factors that influence the benefits of school gardening. Of these, eight were about plants, seven about activities, two about outdoor environments, and three about other participants. Most of the factors provide more than one benefit. The factors with the greatest impact have the most number of benefits that influence children and include "appearance, odor and texture," "hands-on," and "outdoor natural elements." These factors help us to realize the unique characteristics of gardening, highlight the distinctiveness, and increase the indispensability of gardening activities.

$\mathrm{T}$ The concept of school gardens is not new. They were used in parts of Europe as early as the 19 th century and the first recorded school garden in the United States was established in 1891 in Massachusetts (Bucklin-Sporer and Pringle, 2010). Over the last 20 years, school gardening has become a growing movement nationwide in the United States (Blair, 2009). As the popularity of school gardening has grown, the amount of research examining the benefits of gardening activities for

This study was supported in part by the National Science Council of Taiwan (NSC 100-2410-H-002170-MY2).

We would like to thank Eric Shih for assistance with editing and English grammar.

${ }^{1}$ Department of Horticulture and Landscape Architecture, National Taiwan University, No. 1, Sec. 4, Roosevelt Road, Taipei City, 10617, Taiwan

${ }^{2}$ General Education Center, Chang Jung Christian University, No. 1, Changda Road, Tainan City, 71101, Taiwan

${ }^{3}$ Corresponding author. E-mail: cycmail@ntu.edu.tw. doi: 10.21273/HORTTECH03074-16 children has also increased. Some of the benefits identified from these studies include increasing children's life skills such as gaining selfesteem (Alexander et al., 1995; Montessori, 1912; Sarver, 1985) and self-understanding (Robinson and Zajicek, 2005), giving children pleasant experiences (Alexander et al., 1995; Schimmel, 2004; Waliczek et al., 2001), improving interactions with other people (Alexander et al., 1995; Canaris, 1995; Dirks and Orvis, 2005; Laksoharju et al., 2012), increasing children's knowledge of the environment (Canaris, 1995; Dirks and Orvis, 2005; Kahtz, 1995), giving children insight into healthy eating and nutrition (Canaris, 1995; Koch et al., 2005; Morris and
Zidenberg-Cherr, 2002), increasing children's willingness to eat vegetables (Langellotto and Gupta, 2012; Lineberger and Zajicek, 2000), and increasing connection to nature (Canaris, 1995; Waliczek et al., 2001).

While the school gardening movement has been popular for many years around the world, it has only recently taken hold in Taiwan. Furthermore, the opportunities for children to be in contact with nature and experience gardening activities in Taiwan may be fewer in comparison with children in Europe or North America. This is because most people in Taiwan live in apartment buildings within cities (Directorate-General of Budget, Accounting and Statistics, Executive Yuan, 1995). In contrast to the suburban model of habitation found in North America, in Taiwan there are very few single-family homes with yards; so many Taiwanese children have few opportunities to engage with gardening because of limited space in their residences. Since the emphasis on academic work is significant and with school occupying much of their day, students in Taiwan do not have much free time to spend outdoors. About half of the students in Taiwan spend even more time attending after-school tutoring centers, commonly known as "cram schools" (Wei, 2011).

The situation is changing in Taiwan. In the past few years, a few elementary schools have started to develop gardening activities in school. One purpose of this study was to see how gardening could positively influence the children in Taiwan. For comparison, research has found that children in North America enjoyed gardening programs and wanted to participate in more gardening type activities (Dirks and Orvis, 2005). For this study, the researchers also wanted to explore whether children in Taiwan would have the same affinity for gardening.

While there is a large body of research assessing the benefits that gardening activities provide for children, there are very few studies examining which factors influence these

\begin{tabular}{llll}
\hline $\begin{array}{l}\text { Units } \\
\begin{array}{l}\text { To convert U.S. to SI, } \\
\text { multiply by }\end{array}\end{array}$ & U.S. unit & SI unit & $\begin{array}{l}\text { To convert SI to U.S., } \\
\text { multiply by }\end{array}$ \\
\hline 0.3048 & $\mathrm{ft}$ & $\mathrm{m}$ & 3.2808 \\
0.0929 & $\mathrm{ft}^{2}$ & $\mathrm{~m}^{2}$ & 10.7639
\end{tabular}


benefits. Currently, only a small number of these factors have been identified from interview records in a limited number of qualitative studies. Alexander et al. (1995) found from their interviews that enjoyable experiences came from tangible outcomes and from interacting with others during activities. Understanding influencing factors is very important in helping to identify the unique features that distinguish gardening activities from other types of experience-based activities. In addition, when designing gardening activities and establishing objectives, appropriate factors of influence can be selected, which in turn can increase the effectiveness of programming these activities for children.

The majority of studies have used traditional quantitative research methodologies to assess the effects of gardening activities. However, advocates of qualitative methods argue that the results of quantitative analysis are not always meaningful when they are transferred to a natural environment (Waliczek et al., 2003). Blair's (2009) review of the literature on school gardening points out that qualitative studies produce a wider range of findings. Therefore, this study uses a general inductive approach, which can be easily applied and has a systematic set of procedures for analyzing qualitative data (Thomas, 2006) to gain insight into the benefits of school gardening for children in Taiwan and to further identify factors influencing these benefits. By choosing qualitative research methods, this study was able to probe deeply into the rich answers given by participants.

\section{Materials and methods Samples}

This study used purposeful sampling to select participants. To understand as fully as possible the benefits of school gardening and associated influencing factors, this study selected elementary students identified as having extensive experience in gardening activities as participants. To start, the researchers found schools with existing gardening programs and then contacted each school's academic affairs office for permission to conduct the study and to select students who have had significant experience with gardening.
The researchers decided to narrow the selection to students in the fifth and sixth grades (typically 10-12 years of age), the two highest grade levels at the school. These students would have the most experience with gardening at the school. Finally, the researchers selected and interviewed students at each school based on teacher recommendations and the students' willingness to participate. Using this selection criteria, between four and nine students were interviewed at each school.

The researchers used the concept of theoretical saturation (Glaser and Strauss, 1967) to determine sample size. This means that when no additional data are obtained from additional interviews, data collection is considered completed. This sampling strategy mirrors Lincoln and Guba (1985), who stated "the sampling is terminated when no new information is forthcoming from new sampled units; thus redundancy is the primary criterion." After analyzing the interviews from 18 participants from two schools in Taipei, it was clear that all benefit concepts had emerged. No new benefits emerged in the analysis of the student interviews at the next two Taipei schools or other schools located in different parts of Taiwan. At that point, the researchers decided that the data collection was completed. A total of 43 participants were interviewed from six schools.

\section{Schools}

The six schools were all public schools. Four of them were located in suburban Taipei, the other two (School D and School F) were located in rural areas of central and southern Taiwan (Table 1). The enrollment at the schools ranged from 100 to about 400 students, except for School D, which had 21 students (Table 1).

\section{Gardening programs}

All the schools had existing gardening programs before this study. Most students in the six schools would have their first school gardening experience in grade one, the latest would be by grade three. All schools offered gardening to students for two or more grade levels (Table 1). Every school gardening program in this study included the experience of growing vegetables. Most schools also had students growing flowers and fruits. Schools also used local crops in their programs. School D grew grapes (Vitis vinifera) and Schools A and F grew rice (Oryza sativa). The gardening programs were designed and taught by teachers at each school. Most of the teachers had a formal background in science or personal experience with gardening.

Each school found gardening environments suitable for the gardening programs. Most schools had outdoor gardening plots on their property. A couple of the schools borrowed space from neighboring farmers. One school even rented some space from a farm. Some schools used planters or pots within classrooms or outside the classroom in an outdoor corridor (Table 1).

\section{Curriculum}

Each school in this study developed its own curriculum for the gardening programs. There is no national curriculum for school gardening in Taiwan. However, many schools follow the grade three curriculum guidelines for science and technology from the Ministry of Education, which includes a short section about understanding animal and plant growth, to determine what students should learn. The guidelines suggest that in grade three, students should understand how plants grow, learn the parts of a plant, and learn planting techniques (K-12 Education Administration, Ministry of Education, 2008).

In each of the six schools, the curriculum to grow vegetables was very similar. They included plant identification, plant anatomy, choosing the suitability of vegetables, tool usage, soil preparation, fertilizer application, transplanting plants, seed sowing, watering, weeding, pest control, observing plant growth and flowering, harvesting, and record keeping. For Schools A and F, the curriculum also included topics specific to rice such as growing seedlings, transplantation, and harvesting. School D included growing grapes in its curriculum and topics such as thinning and bagging. All schools offered gardening weekly for sessions ranging from $40 \mathrm{~min}$ to $2 \mathrm{~h}$ for 5 to 40 weeks per year (Table 1). Most schools allowed the students to take home parts of their harvested vegetables, fruits, and rice. Schools D and 


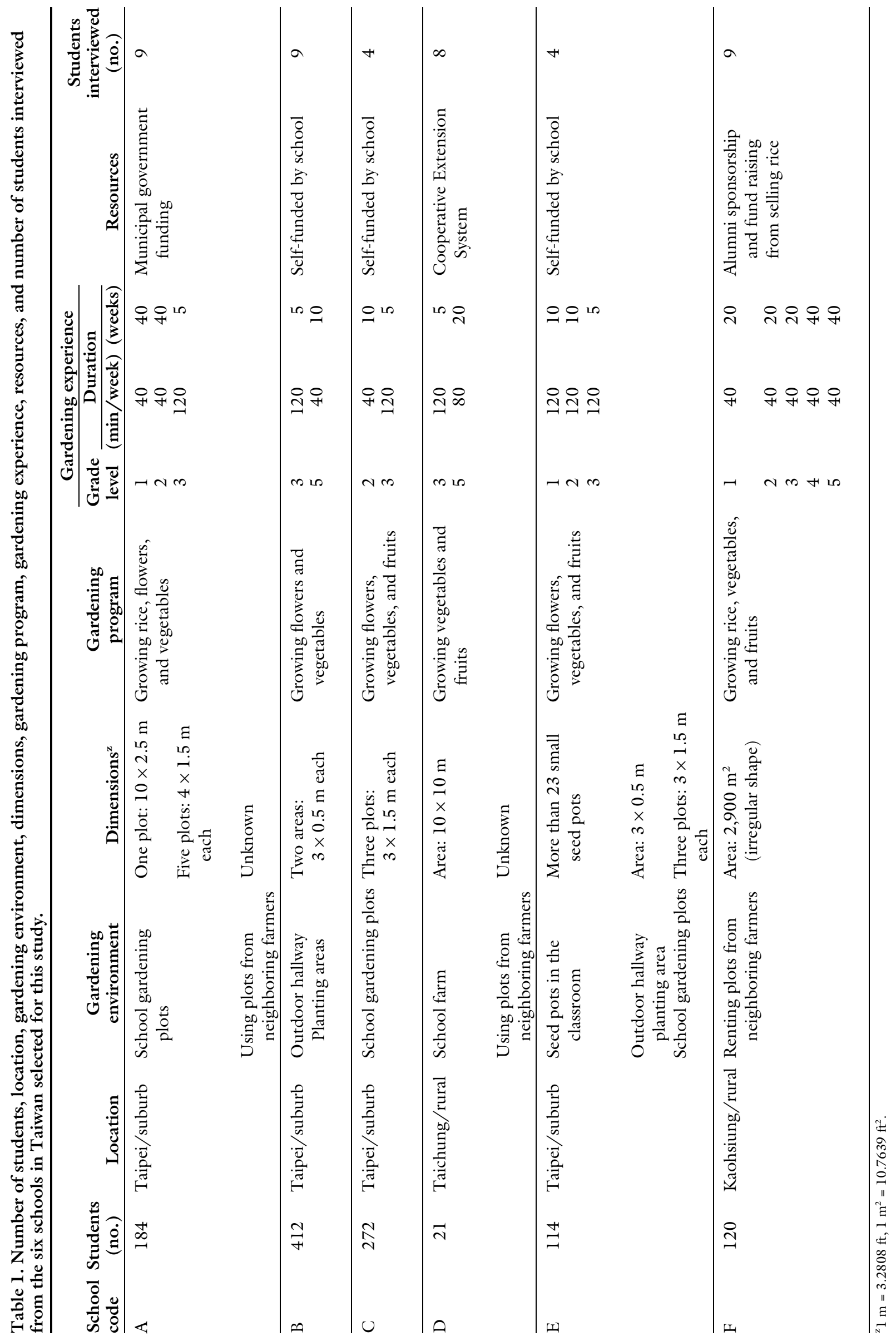


F also used part of their harvested vegetables and rice for school lunches.

\section{Data collection}

The data collection consisted of first a pre-interview worksheet questionnaire and then an interview section. The researchers designed this in accordance with Punch (2002) who indicated that since "most of the young people from the school sample had had limited experience of direct communication with an unfamiliar adult in a one-to-one situation," by having a pre-interview worksheet, the respondents would be more familiar with the type of questions that would be asked.

Pre-interview. Before being interviewed, each participant was required to fill out a pre-interview worksheet questionnaire. The worksheet included one closed-ended question and three open-ended questions. The closed-ended question was, "Do you like to grow plants?" This question was measured using five-point Likert-type scale which included the responses "strongly like," "somewhat like," "neither like nor dislike," "somewhat dislike," and "strongly dislike." The three openended questions were 1) "Which plants have you grown before?" 2) "What do you think when you look at plants, such as flowers, grass, and trees?" 3) "What did you think about when you were growing plants?" The purpose of the worksheet was to help participants recall their experiences in advance of the interview and enable the interviewer to ask follow-up questions related to their answers. Punch (2002) indicated that using a task-based activity, such as a worksheet would be useful for both stimulating discussion and generating more easily comparable data. This was helpful because, for some students, 1.5 years had passed between when the gardening activities occurred and when the interviews were given.

INTERVIEW. One researcher conducted all the interviews, which were done at the schools in either a meeting room or library during the school day using face-to-face and semistructured interview methods. Three to four participants were in each session and no teacher or other adults were present. The interviewer spoke with each participant separately, with the other participants doing other tasks. Each individual participant interview took about $15 \mathrm{~min}$. The interviews included asking why the participant answered how they did for the closed-ended question, "Do you like to grow plants?" The interviewer also re-asked questions from the worksheet: "What do you think when you look at plants, such as flowers, grass, and trees?" and "What did you think about when you were growing plants?" The interviewer then asked additional questions: "What are some of your experiences of growing plants?" and "What impresses you while growing plants?" The interviewer would further probe the answers given by participants with a "why" question to get more details. At the end of the interview session, the interviewer would gather all the participants together and ask them if there was anything else they forgot to mention or wanted to add to their comments. All the interview questions followed Patton's (1990) general guidelines for qualitative questioning such as using openended questions and follow-up questions. These questions were checked for validity though discussions with senior faculty members in the Department of Horticulture and Landscape Architecture at National Taiwan University.

\section{Data analysis}

Interview tapes were transcribed. A general inductive approach (Thomas, 2006) was used to analyze the transcripts. The analytical process was as follows: one researcher prepared the raw data file, which included a visual notation of the facial expression of the participants. Next both researchers conducted a close reading of the text, coded, and determined the categories of benefits of gardening. Afterward, the researchers identified the factors affecting gardening from the data. For example, a participant said, "One day, the plant suddenly bloomed, and everyone in our class went to see. And I felt so joyful, that experience was so special." Within this sentence, the researchers would identify, "I felt so joyful" as a benefit and "the plant suddenly bloomed" as a factor

The next step involved combining the independently coded data files, and processing the overlapping coded and uncoded text. In addition, checks on the clarity of categories developed by each researcher were carried out and necessary revisions were made until a consensus was reached. A third researcher checked the results of the analysis. Additionally, researchers used quantitative analyses to look at gender differences.

The data were analyzed using SPSS (version 22; IBM, Armonk, NY). The differences in preference of gardening between Taiwanese boys and girls were tested using independent $t$ test analyses. The researchers used chi-square test to compare the differences between Taiwanese boys and girls who identified the same benefit.

\section{Credibility and dependability}

This study followed the methodology recommended by Thomas (2006) to ensure the credibility of the findings by having two of the researchers with training in qualitative research and with analytical research capabilities carry out the analysis via independent parallel coding. As a control for dependability according to Lincoln and Guba (1985) and Thomas (2006), the study used the stepwise replication of the independent parallel coding of two researchers and a research audit conducted by a third researcher.

\section{Results and discussion}

In this study, 20 boys and 23 girls, for a total of 43 children, were interviewed. Discussion of the results will be in three sections on the basis of research objectives and the content of the interview responses. The first section relates to the level of preference for gardening activities, the second section discusses the benefits children derive from gardening activities, and the final section investigates the factors that influence the benefits of gardening.

\section{Children's preferences for gardening}

The results show that most participants have positive feelings about school gardening. Of the participants, $79.1 \%$ replied that they like and strongly like to grow plants (Table 2). Most participants mentioned that gardening is an "interesting" (no. 18) and "fun" (no. 2) activity that could provide many surprises and 
pleasures. This is consistent with the finding by Dirks and Orvis (2005) about children's enjoyment of gardening programs and desire for more gardening type activities.

This study also found that there were differences in preference for gardening between Taiwanese boys and girls $[P \leq 0.001$ (Table 2)]. A greater percentage of boys $[\mathrm{n}=19$ $(95.0 \%)]$ stated they like or strongly like to grow plants compared with girls $[\mathrm{n}=15(65.2 \%)]$ (Table 2). The girls interviewed who stated that they neither liked nor disliked plants $[\mathrm{n}=7$ (30.4\%)] or somewhat disliked plants $[\mathrm{n}=1(4.3 \%)]$ gave the following explanations as to why: after watering or digging, many insects and worms would appear from the soil, which they found "disgusting" (no. 4). One participant said that she had spent a lot of time looking after the plant, but, in the end, it died, making her "very sad" (no. 3). Some boys also noted that they were uncomfortable when "seeing insects and worms in the soil" (no. 32); however, they still viewed gardening as a very enjoyable activity. They did not let the presence of insects and worms affect their affinity for gardening.

Davey et al. (1998) conducted a cross-cultural study of animal fears. In that study, researchers found that in most countries, females had higher fear ratings than males for "disgustrelevant animals" such as worms. Also noteworthy from this study, was the discovery that overall fears of worms in Asian countries such as Japan, Korea, and Hong Kong were greater than in the United Kingdom and the United States.

\section{The benefits of school gardening}

Seven main groupings of benefits of school gardening emerged in the analysis of the data. They are increasing life skills, producing pleasant feelings, improving relationships and having plants as companions, acquiring new knowledge, experiencing the aroma and flavor of fruits and vegetables, improving health, and increasing connection to nature (Table 3 ). All participants gave responses that included at least two benefits, with only three participants noting four or fewer benefits. Nine participants noted five benefits, whereas 15 and 16 participants noted six and seven benefits, respectively.

INCREASING LIFE SKILLS. Almost all participants $[\mathrm{n}=40(93.0 \%)]$ gave examples that would fit within the increasing life skills benefit grouping (Table 3). They were self-esteem, a sense of achievement, a sense of responsibility, patience and attentiveness, resilience, a desire to work hard, problem-solving initiative, compassion, and empathy. Most of these life skills have been identified in previous research. Some studies have reported that gardening can increase children's self-esteem (Alexander et al., 1995; Montessori, 1912; Sarver, 1985) and self-understanding (Robinson and Zajicek, 2005). Gardening can give children patience to wait for things to grow (Alexander et al., 1995; Montessori, 1912), pride in their activities (Alexander et al., 1995), a sense of responsibility to care for the plants (Hung, 2004; Sarver, 1985), and a positive attitude to face failure (Schimmel, 2004).

Some benefits such as a desire to work hard, problem-solving initiative, compassion, and empathy are newly identified in this study. For example, participant no. 21 stated, "I have to work harder, because the plants I planted are also working hard to grow." Participant no. 1 expressed, "When growing plants, just don't treat it as a game. You need to have a sense of responsibility, because, after all, a plant is a life. If you grow something and then suddenly give up on it, the plant or flower is very unfortunate." Some participants spoke about how they would then try to find a method to help keep the plant alive, such as asking the teacher for help or doing their own research in places like bookstores or

Table 2. Responses by gender to the question, "Do you like to grow plants?," and comparison of the responses by gender using an independent $t$ test for the study titled "Exploring the Benefits of School Gardening for Children in Taiwan and Identifying the Factors Influencing These Benefits."

\begin{tabular}{|c|c|c|c|c|c|c|c|c|c|c|c|c|c|c|}
\hline Gender/preference & \multicolumn{2}{|c|}{$\begin{array}{c}\text { Strongly } \\
\text { dislike }\end{array}$} & \multicolumn{2}{|c|}{$\begin{array}{c}\text { Somewhat } \\
\text { dislike }\end{array}$} & \multicolumn{2}{|c|}{$\begin{array}{l}\text { Nether like nor } \\
\text { dislike }\end{array}$} & \multicolumn{2}{|c|}{$\begin{array}{c}\text { Somewhat } \\
\text { like }\end{array}$} & \multicolumn{2}{|c|}{$\begin{array}{c}\text { Strongly } \\
\text { like }\end{array}$} & Mean & SD & $t$ & $P$ value \\
\hline Boy $(\mathrm{n}=20)$ & 0 & 0.0 & 0 & 0.0 & 1 & 5.0 & 8 & 40.0 & 11 & 55.0 & 4.50 & 0.61 & 1.47 & 0.001 \\
\hline $\operatorname{Girl}(n=23)$ & 0 & 0.0 & 1 & 4.3 & 7 & 30.4 & 3 & 13.1 & 12 & 52.2 & 4.13 & 1.01 & & \\
\hline Total $(\mathrm{n}=43)$ & 0 & 0.0 & 1 & 2.3 & 8 & 18.6 & 11 & 25.6 & 23 & 53.5 & & & & \\
\hline
\end{tabular}

${ }^{\mathrm{z}}$ Statistically highly significant if $P \leq 0.001$.

Table 3. The number and percentages of Taiwanese boys and girls in this study who identified each of the benefits of school gardening and comparison between boys and girls who identified the same benefit using a chi-square test.

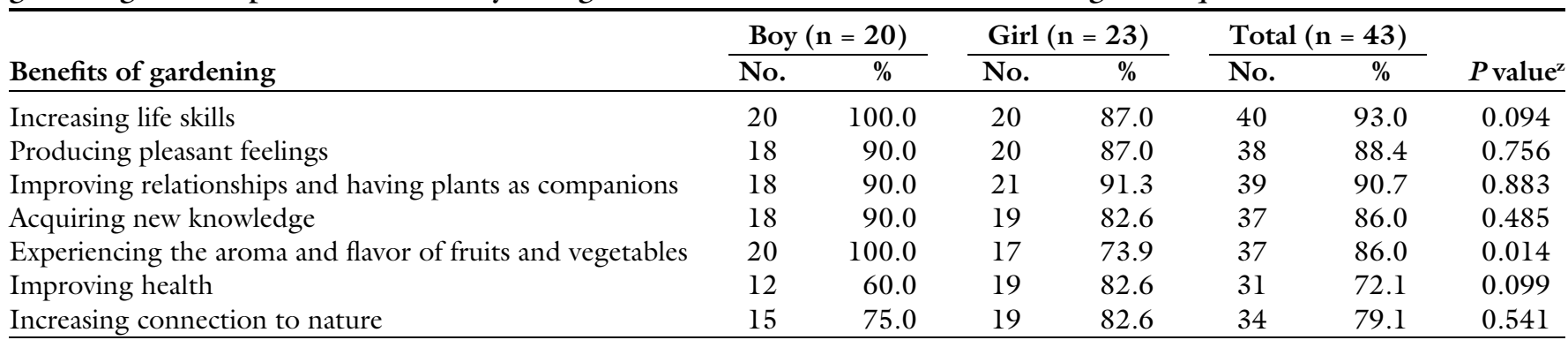

${ }^{\mathrm{z}}$ Statistically significant if $P \leq 0.05$ 
the Internet. Furthermore, some participants also said that after their hands-on experience with gardening, they could understand how much work farmers had to do, so they appreciated where their food came from even more.

Producing Pleasant feelings. Most participants $[\mathrm{n}=38(88.4 \%)]$ expressed that gardening produced pleasant feelings (Table 3 ). Researchers based this observation on some of the words participants used to describe how gardening made them feel. They included: "fun" (no. 30), "happy" (no. 13), "moved" (no. 3), "excited" (no. 35), "surprised" (no. 14), and "comfortable" (no. 9). Some participants said that they were happy when they saw their plants grow successfully. For example, participant no. 17 said, "watching the plants steadily grow up, when they are finally grown, I am very happy." In addition, some participants were pleased that they could spend time outdoors and outside the classroom to garden. This finding supports past research that gardening can give children pleasant experiences (Alexander et al., 1995; Schimmel, 2004; Waliczek et al., 2001).

IMPROVING RELATIONSHIPS AND HAVING PLANTS AS COMPANIONS. Many participants $[\mathrm{n}=39(90.7 \%)]$ said that when they gardened, classmates often helped one another by sharing information and personal gardening tips (Table 3 ). Participant no. 22 expressed, "you might find that the plants have been eaten by insects, or that the plant has withered because you gave it too much water. When this happens I can exchange experiences with good friends...my friends and classmates. This is the way to grow plants well, and you also get to increase your friendship!" This supports the findings of past studies, which showed that gardening increases interactions among people (Alexander et al., 1995; Canaris, 1995; Dirks and Orvis, 2005; Laaksoharju et al., 2012).

In addition, some participants also said that gardening makes them view plants as being like friends or even family. "I think that talking to them (plants) is fun. You can tell them what's on your mind! And then... ah...they do not show any expression, nor have any reaction. You can just speak what's on your mind. If you are in a bad mood you can talk to them. It can make you feel a little bit better" (no. 20). While this finding is mentioned by only a minority of participants, it has not been identified in previous studies, and is, therefore, an important research finding. A possible explanation could be that people of Chinese or Taiwanese background are not socialized to openly express their own personal emotions, especially strong negative ones (Samovar et al., 2010). Therefore, the perceived companionship that plants offer can provide an important source of support, emotional comfort, and release for children.

ACQUiRING NeW KNOWLEDGe. Many participants $[\mathrm{n}=37(86.0 \%)]$ described learning about taking care of plants, using the experimental method to grow plants, and gaining knowledge about plants and insects from their hands-on experience with gardening (Table 3 ). This is consistent with the findings of past studies about knowledge through gardening (Alexander et al., 1995; Canaris, 1995; Dirks and Orvis, 2005; Mabie and Baker, 1996).

EXPERIENCING THE AROMA AND FLAVOR OF FRUITS AND VEGETABLES. Most participants $[\mathrm{n}=37 ; 86.0 \%)]$ stated that they were willing to taste vegetables and fruits they planted, even if they had not eaten them before (Table 3 ). Some participants remarked that some fruits and vegetables they grew tasted different from ones found at the market. Theirs were "tastier" (no. 26) and they felt more "secure" (no. 23) eating their own grown produce compared with what was commercially available. Participant no. 39 said, "When it is time to harvest and you pick the tomato to eat, it really tastes great, both sweet and sour. I hope next time I can plant tomatoes again" [tomato (Solanum lycopersicum)]. The interviewer also observed that every time the participants spoke about eating their own harvested food, they did so with satisfaction. Other researchers have also found that gardening gives children insight into healthy eating and nutrition (Canaris, 1995; Koch et al., 2005; Morris and Zidenberg-Cherr, 2002), and that it increases their willingness to eat vegetables (Langellotto and Gupta, 2012; Lineberger and Zajicek, 2000).
Improving HeALTH. In Taiwan, the amount time spent on studying and homework by elementary students can result in a lot of pressure (Chen et al., 2006). Many participants $[\mathrm{n}=31(72.1 \%)]$ said that gardening made them feel relaxed and helped them relieve their pressures from school and worries about troubles (Table 3). "I think gardening is very fun...I can also talk to them and tell them what I am thinking. Afterward, the heavy weight that I carry inside disappears" (no. 10). Research has explored how plants or natural scenery have had restorative or stress-reducing effects (Chang and Chen, 2005; Hartig et al., 2003; Kaplan and Kaplan, 1989; Ulrich, 1981; Ulrich et al., 1991). However, most of the studies focused on adults. The findings of this study may show that participating in gardening may have positive impacts on the mental well-being of children. Some participants $[\mathrm{n}=14(32.6 \%)]$ said gardening also helped them with their physical health by helping them increase stamina, lose weight, and relieve eye fatigue.

INCREASING CONNECTION TO NATURE. As each school in this study conducted part of their gardening activities in outdoor areas, many participants $[\mathrm{n}=34(79.1 \%)]$ said that gardening allowed them to spend more time outdoors and also allowed them to connect with plants, insects, soil, sun, wind, and water (Table 3 ). Participant no. 33 said, "one time when I was growing pomelos, a small white and green bug jumped onto one of the plants' leaves. And it started to eat the leaf .... It then stayed on the plant and made a cocoon and eventually turned into a butterfly. I took a video of it .... After a few days, it came out and after an hour, it flew away" [pomelo (Citrus grandis)]. This finding supports past research that gardening increases connection to nature (Canaris, 1995) and also gives children important interactions with the natural world (Waliczek et al., 2001).

Demographic COMPARISONS. This study found that there were some differences between Taiwanese boys and girls in identifying benefits of school gardening (Table 3 ). For example, all boys $[\mathrm{n}=20(100 \%)]$, as compared with girls $[\mathrm{n}=20(87 \%)]$, identified "increasing life skills" as 
a benefit. More girls [ $\mathrm{n}=19(82.6 \%)]$, as compared with boys $[\mathrm{n}=12$ $(60.0 \%)]$, identified "improving health" as a benefit. The only statistically significant difference was that boys $[\mathrm{n}=$ $20(100.0 \%)]$ had identified "experiencing the aroma and flavor of fruits and vegetables" as a benefit more than the girls $[\mathrm{n}=17(73.9 \%)][P \leq$ 0.05 (Table 3)].

\section{Factors that influence the benefits of gardening}

This study found 20 factors that influence the benefits of gardening. Of these, eight were about plants, seven about activities, two about outdoor environments, and three about other participants (Table 4). Most of the factors provided more than one benefit. For example, the factor "plants have life" provides three benefits of gardening including "increasing life skills," "producing pleasant feelings," and "improving relationships and having plants as companions" (Table 4). For this study, three factors had a greater number of benefits reported by children. They included "appearance, odor and texture," "hands-on," and "outdoor natural elements" (Table 4).

Appearance, ODOR, AND TEXTURE. There were 33 participants $(77.0 \%)$ who mentioned physical characteristics of plants like appearance, odor, and texture (Table 4). They often noticed these factors first, which had a significant impact on their impressions. From the scent of flowers to the shape and color of vegetables, children often used all five senses to interact with plants and establish their relationship with them including an emotional connection $[\mathrm{n}=11(25.6 \%)]$. Participant no. 3 said, "If the plant I grow is beautiful and full of life, I will feel happy and moved." Participant no. 21 stated, "when I saw the plants I have a sunny feeling. (I felt) I have to work harder." Ulrich (1983) also supports this point that natural elements, such as vegetation, can evoke positive emotions. Participant no. 36 also noted that seeing plants made him feel comfortable, "I feel as though I am in my own world, away from the other world where everyone has to do homework."

HANDS-ON. This study found that the "hands-on activity" factor was very important with 42 participants
(97.7\%) mentioning it (Table 4). Some studies have pointed out that gardening can provide the opportunities to engage in a "hands-on activity" (Lineberger and Zajicek, 2000; Waliczek et al., 2003). This factor contributes to six benefits (Table 4). Participant no. 7 said, "before, every time I saw other people grow flowers, I only noticed how beautiful the flowers are. I often didn't realize that growing flowers takes a lot of hard effort. However, after my own handson experience, I truly realized that growing flowers is hard work. Seeing the flowers bloom, makes me realize that the hard effort is worth it." Although other activities may offer hands-on experiences, gardening offers a distinct set of benefits. Some examples included greatly enhancing and also inspiring a sense of achievement and empathy as well as promoting learning. For example, nine participants $(21.0 \%)$ said that because of their own hands-on experiences, they could understand the hardships that farmers face, which helped develop a sense of empathy.

OUTDOOR NATURAL ELEMENTS. Most participants [ $\mathrm{n}=29(67.4 \%)]$ noted some elements found outdoors such as soil, insects, the breeze, the coolness of the plants, and the warm sun would be beneficial (Table 4). They said these outdoor elements could help them relax and temporarily forget their troubles. "When I see flowers and trees I feel very relaxed. After I see them, I start to daydream. In the classroom, there is a lot of work the teacher has for us to learn on the chalkboards, such as mathematics and Chinese. So seeing the plants helps me to relax" (no. 1). Other studies also showed that natural environment plays a significant role in the wellbeing of children, such as cognitive functioning (Wells, 2000) and attention (Taylor et al., 2001).

Additionally, this study identified other factors that are notable such as peer involvement $[\mathrm{n}=36$ $(83.7 \%)]$ and guidance of instructors $[\mathrm{n}=22(51.2 \%)]$ (Table 4). While gardening can be beneficial when done solo, there are additional benefits from gardening when working with others. One participant said that gardening with friends made her even happier (no. 34) and another participant noted, "everyone can help each other (when gardening)" (no. 32).
Blair (2009) stated that the guidance of instructors is the major variable in school gardening success. In this study, half the participants mentioned that they often did not know how to grow the plants or that the plants that they grew would die. However, with a teacher's guidance, they were able to successfully grow plants and keep them healthy and alive.

This study identified the benefits of gardening for children and also found the number of factors that influence the benefits are not few. These factors help one to realize the unique characteristics of gardening, and also highlight the distinctiveness and increase the indispensability of gardening activities. For example, gardening is different from other activities like art or music because plants are alive and can grow. Children can see sprouting, germination, flowering, fruit production, and that the plant's appearance can differ over time. Each of these changes in appearance represents a return for the children's hard work, thus motivating them with a sense of achievement. The children can also experience compassion and empathy because they realize the value of life.

When designing gardening programs, teachers may want to consider how factors can influence the types of benefits children might get from gardening activities. By targeting certain factors, they can better achieve desired outcomes and benefits. For example, teachers who want to enhance student relationships may consider incorporating the "peer involvement," "hands-on," "requires skills," and "fun and interesting," factors when designing activities. Teachers can also incorporate activities to be more complicated or challenging to let children work cooperatively to solve the task. To gain benefits, the entire process should allow children enough time required to do activities such as soil preparation, planting, growing, and harvesting. By choosing plants that have a specific appearance, odor, or texture, for a gardening activity, teachers can attract children's attention and provide a discussion point. Also, as children harvest and eat the plants they grow, teachers can discuss the flavors of the food, highlight nutrition by using the food pyramid, and create a sharing environment. While this next finding will 


\section{Research Reports}

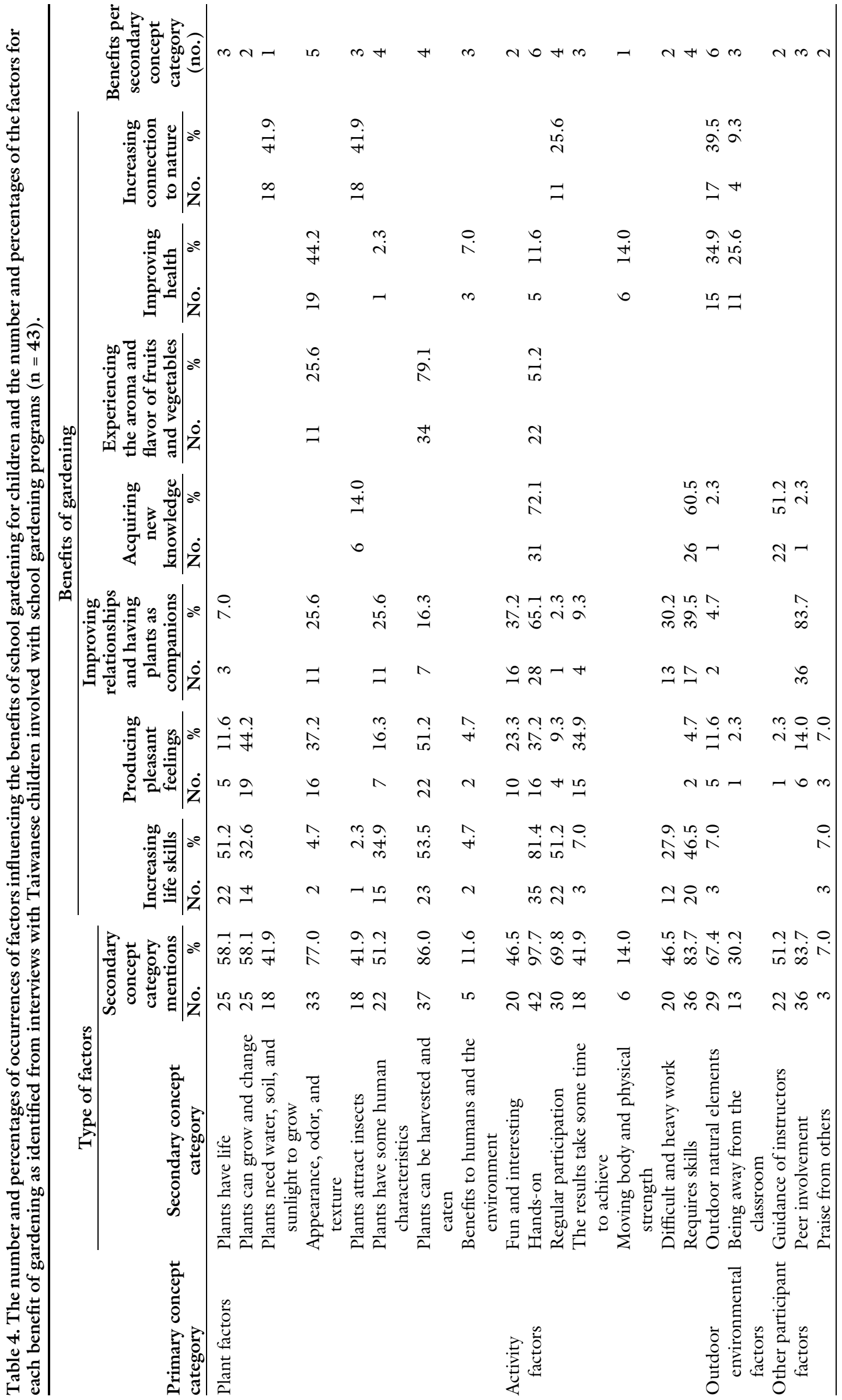


require further investigation, a review of the data leans toward the notion that perhaps gardening could be more beneficial for girls in Taiwan and contribute to better health outcomes for them. Since girls spend less time outside when compared with boys and are less physically active in Taiwan (Ministry of Education, 2015), they may benefit from more opportunity to be active outdoors. As the interviews showed negative reactions to soil and insects from some girls, teachers could start introducing some concepts of gardening to girls at a lower grade level, specifically introducing such things as soil and insects to give girls more familiarity to what is found outdoors.

Researchers asked respondents to recall their past experiences of participation in gardening activities to gain a full understanding of their feelings after engagement in a range of gardening activities, and to find influence cause and effect. Due to the passage of time from when the gardening activity took place to the time of the interview, it is difficult to avoid the possibility that the respondents may have forgotten some of their feelings. Therefore, it is recommended that future studies carry out assessments immediately after the gardening classes have concluded, using the accumulated interview data to achieve a more precise understanding.

\section{Literature cited}

Alexander, J., M. North, and D.K. Hendren. 1995. Master gardener classroom garden project: An evaluation of the benefits to children. Children's Environ. 12: 123-133.

Blair, D. 2009. The child in the garden: An evaluative review of the benefits of school gardening. J. Environ. Educ. 40: 15-38.

Bucklin-Sporer, A. and R.K. Pringle. 2010. How to grow a school garden: A complete guide for parents and teachers. Timber Press, Portland, OR.

Canaris, I. 1995. Growing foods for growing minds: Integrating gardening and nutrition education into the total curriculum. Children's Environ. 12:134142.

Chang, C. and P. Chen. 2005. Human responses to window views and indoor plants in the workplace. HortScience 40:1354-1359.

Chen, C., L. Lin, P. Ying, W. Liu, and N. Liu. 2006. Evaluation of the correlation between the learning stress and the myopia incidence of the elementary school students by one year of longitudinal surveys. J. Health Educ. 25:1-26.

Davey, G.C.L., A.S. McDonald, U. Hirisave, G.G. Prabhu, S. Iwawaki, C.I. Jim, H. Mercklbach, P.J. de Jong, P.W.L. Leung, and B.C. Reimann. 1998. A cross-cultural study of animal fears. Behav. Res. Ther. 36:735-750.

Directorate-General of Budget, Accounting and Statistics, Executive Yuan. 1995. Population and housing survey in Taiwan. 29 Mar. 2016. <http://www.stat. gov.tw/public/Attachment/07611193571. pdfs.

Dirks, A.E. and K. Orvis. 2005. An evaluation of the junior master gardener program in third grade classrooms. HortTechnology 15:443-447.

Glaser, B.G. and A.L. Strauss. 1967. The discovery of grounded theory: Strategies for qualitative research. Aldine, Chicago, IL.

Hartig, T., G.W. Evans, L.D. Jamner, D.S. Davis, and T. Garling. 2003. Tracking restoration in natural and urban field settings. J. Environ. Psychol. 23:109-123.

Hung, Y. 2004. East New York Farms: Youth participation in community development and urban agriculture. Child. Youth Environ. 14:56-85.

K-12 Education Administration, Ministry of Education. 2008. Grade 1-9 curriculum guideline for science and technology. 27 July 2016. <http://www.kl2ea.gov. tw/97_sid 17/\%E8\%87\%AA\%E7\%84\% B6\%E8\%88\%87\%E7\%94\%9F\%E6\%B4\% BB\%E7\%A7\%91\%E6\%8A\%80970917\% E5\%AE\%9A\%E7\%A8\%BF\%E5\%96\%AE\% E5\%86\%8A.pdf>.

Kahtz, A.W. 1995. Impact of environmental education classes at Missouri Botanical Garden on attitude and knowledge change of elementary school children. HortTechnology 5:338-340.

Kaplan, R. and S. Kaplan. 1989. The experience of nature: A psychological perspective. Cambridge Univ. Press, New York, NY.

Koch, S., S. Lineberger, and J.M. Zajicek. 2005. Can an educational program on the nutritional benefits of citrus fruit positively influence the nutritional attitudes of children? HortTechnology 15:468-476.

Laaksoharju, T., E. Rappe, and T. Kaivola. 2012. Garden affordances for social learning, play, and for building nature-child relationship. Urban For. Urban Green. 11: 195-203.

Langellotto, G.A. and A. Gupta. 2012. Gardening increases vegetable consumption in school-aged children: A metaanalytical synthesis. HortTechnology 22: 430-445.

Lincoln, Y.S. and E.G. Guba. 1985. Naturalistic inquiry. Sage, Beverly Hills, CA.

Lineberger, S.E. and J.M. Zajicek. 2000. School garden: Can a hands-on teaching tool affect students' attitudes and behaviors regarding fruit and vegetables? HortTechnology 10:593-597.

Mabie, R. and M. Baker. 1996. The influence of experiential instruction on urban elementary students' knowledge of the food and fiber system. J. Ext. 34:1-4.

Ministry of Education. 2015. Educational statistical newsletter, No. 38. 8 May 2016. <http://stats.moe.gov.tw/files/ brief/\%E6\%88\%91\%Е5\%9C\%8B\%E4\% B8\%AD\%E7\%AD\%89\%E4\%BB\%A5\%E4\% B8\%8B\%E5\%AD\%B8\%E6\%A0\%Al\%E5\% AD\%B8\%E7\%94\%9F\%E5\%81\%A5\%E5\% BA\%B7\%E7\%8B\%80\%E6\%B3\%81\%E4\% B9\%8B\%E6\%80\%A7\%E5\%88\%A5\%E6\% 85\%8B\%E6\%A $8 \%$ A3\%E5\%88\%86\% E6\% 9E\%90.pdf>.

Montessori, M. 1912. The Montessori method. Schocken, New York, NY.

Morris, J. and S. Zidenberg-Cherr. 2002. Garden-enhanced nutrition curriculum improves fourth-grade school children's knowledge of nutrition and preference for vegetables. J. Amer. Dietetic Assn. 102:91-93.

Patton, M. 1990. Qualitative evaluation and research methods. Sage, Newbury Park, CA.

Punch, S. 2002. Research with children: The same or different from research with adults? Childhood 9:321-341.

Robinson, C.W. and J.M. Zajicek. 2005. Growing minds: The effects of a one-year school garden program on six constructs of life skills of elementary school children. HortTechnology 15:453-457.

Samovar, L.A., R.E. Porter, and E.R. McDaniel. 2010. Communication between cultures. Wadsworth, Belmont, CA.

Sarver, M.D. 1985. Agritherapy: Plants as learning partners. Academic Therapy 20:389-396.

Schimmel, B.S. 2004. Horticultural therapy in a classroom for learning disabled children. J. Therapeutic Hort. 15:36-40.

Taylor, A.F., F.E. Kuo, and W.C. Sullivan. 2001. Coping with ADD: The surprising 


\section{Research Reports}

connection to green play settings. Environ. Behav. 33:54-77.

Thomas, D.R. 2006. A general inductive approach for analyzing qualitative evaluation data. Amer. J. Eval. 27:237-246.

Ulrich, R.S. 1981. Natural versus urban scenes: Some psychophysiological effects. Environ. Behav. 13:523-556.

Ulrich, R.S. 1983. Aesthetic and affective response to natural environment, $\mathrm{p}$. 85-125. In: I. Altman and J.F. Wohlwill (eds.). Behavior and the natural environment. Plenum Press, New York, NY.
Ulrich, R.S., R.F. Simons, B.D. Losito, E. Fiorito, M.A. Miles, and M. Zelson. 1991. Stress recovery during exposure to natural and urban environments. J. Environ. Psychol. 11:201-230.

Waliczek, T.M., J.C. Bradley, and J.M. Zajicek. 2001. The effect of school gardens on children's interpersonal relationships and attitudes toward school. HortTechnology 11:466-468.

Waliczek, T.M., P. Logan, and J.M. Zajicek. 2003. Exploring the impact of outdoor environmental activities on children using a qualitative text data analysis system. HortTechnology 13:684-688.

Wei, H. 2011. Survey on children's living conditions in Taiwan. Children's Bureau Ministry of the Interior, Taipei City, Taiwan.

Wells, N.M. 2000. At home with nature effects of "greenness" on children's cognitive functioning. Environ. Behav. 32: 775-795. 